\title{
Thinness in young schoolchildren in Serbia: another case of the double burden of malnutrition?
}

\author{
Visnja Diordjic ${ }^{1}$, Jagoda Jorga ${ }^{2}$, Snezana Radisavljevic ${ }^{3}$, Ivana Milanovic ${ }^{3}$, \\ Predrag Bozic ${ }^{4}$ and Sergej M Ostojic ${ }^{1,2, *}$ \\ ${ }^{1}$ Faculty of Sport and PE, University of Novi Sad, Lovcenska 16, Novi Sad 21000, Serbia: ${ }^{2}$ University of Belgrade \\ School of Medicine, Belgrade, Serbia: ${ }^{3}$ Faculty of Sport and PE, University of Belgrade, Belgrade, Serbia: \\ ${ }^{4}$ National Institute of Sport and Sports Medicine, Belgrade, Serbia
}

Submitted 12 August 2017: Final revision received 28 September 2017: Accepted 23 0ctober 2017: First published online 13 December 2017

\begin{abstract}
Objective: Thinness is rarely highlighted or regularly monitored among children in developed countries although it may be rather frequent and pose a significant risk to children's health. We aimed to describe the prevalence of mild, moderate and severe thinness among young Serbian schoolchildren.

Design: Cross-sectional study of schoolchildren aged 6-9 years. Children were assessed for weight, height and BMI as part of the WHO European Childhood Obesity Surveillance Initiative in Serbia. Thinness grades were defined as genderand age-specific cut-offs for BMI according to the International Obesity Task Force criteria.

Setting: Serbia, September to November 2015.

Subjects: Students ( $n$ 4861) in grades 2 and 3 (6-9 years, 2397 girls).

Results: Overall prevalence of thinness in Serbian schoolchildren was 9.6\%. Mild thinness was clearly the largest category with a prevalence of $7 \cdot 6 \%$, moderate thinness was present in $1.7 \%$ of children and severe thinness was found in $0.3 \%$ of children. OR indicated a significant risk of being thin for girls (1.44 times higher compared with boys) and children attending schools with no health-focused educational programme ( 1.57 times more likely to be thin than peers enrolled in schools with such programmes). In addition, OR for thinness tended to be 1.23 times higher in children living in an economically disadvantaged region of Serbia $(P=0.06)$.

Conclusions: A rather high prevalence of thinness highlights this malnutrition disorder as an emerging health issue that should trigger public health policies to tackle thinness, especially in girls of young age and children living in economically disadvantaged areas.
\end{abstract}

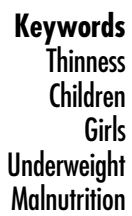

Malnutrition in every clinical form poses a significant risk to children's health ${ }^{(1)}$. Alarming trends in overweight/ obesity of school-aged children in many developed and transitional countries usually focus attention on this public health issue ${ }^{(2)}$. On the other hand, thinness (or underweight) in children has received less scientific scrutiny although it may affect child health, growth and well-being in various ways, including nutritional deficiencies, menstrual irregularity, impaired immune system, osteoporosis, anaemia, anorexia nervosa, hypotension, and decreased cognitive and work capacity ${ }^{(3-6)}$. Parents of thin children reported them to be more often treated adversely or feel insecure because of their weight, to visit the general practitioner and have abdominal pain and allergies more frequently, and to have lower scores on general health in comparison to their normal-weight peers ${ }^{(7)}$. In addition, underweight children demonstrate poorer global health and special health-care needs, with this tendency particularly noticeable in young children ${ }^{(8)}$. However, it was not until 2007 that Cole and co-workers proposed international cut-offs for childhood overweight, obesity and thinness (International Obesity Task Force (IOTF)) ${ }^{(9)}$, thus providing a criterion that makes thinness prevalence countable and comparable. According to national studies using the original or revised IOTF reference system ${ }^{(10)}$, thinness prevalence in young school-aged children in European countries ranges from 1-4\% in Portugal, France and Ireland ${ }^{(11-13)}$, to 6-9\% in England, Sweden, the Netherlands and Lithuania ${ }^{(14-18)}$. As reported by the IDEFICS study ${ }^{(19)}$, thinness prevalence in children aged 2.0-9.9 years 
from eight European countries (Sweden, Germany, Hungary, Italy, Cyprus, Spain, Belgium, Estonia) varied from $5.7 \%$ in Italian boys to $16.6 \%$ in Hungarian girls. Cross-sectional data on thinness prevalence trends are rather consistent, with a slight decline of thinness rate observed in most European countries since the onset of the obesity epidemic ${ }^{(15,16,20-22)}$. However, limited data are currently available for thinness prevalence among schoolaged children in Eastern European countries, considering the dynamic transitional changes in this region that may affect different aspects of children's health ${ }^{(23)}$. Therefore, the main aim of the present cross-sectional study was to collect reliable and internationally comparable data about the prevalence of thinness among 6-9-year-old schoolchildren in Serbia.

\section{Methods}

The present study is based on the first WHO European Childhood Obesity Surveillance Initiative (COSI) in Serbia, which took place during the 2015/16 school year. A detailed description of the Serbian WHO COSI protocol, as well as data on overweight and obesity prevalence, are available elsewhere ${ }^{(24)}$. Briefly, a cross-sectional study targeted schoolchildren aged 6.00-8.99 years, with cluster sampling employed and primary schools and classes selected randomly from the list of all primary schools provided by the education ministry. Stratification by the school district was applied to ensure a nationally representative sample of primary schools. Trained examiners carried out anthropometric measurements in private rooms in participating schools. Children were measured without shoes, in their everyday clothes, with body weight additionally corrected for an average weight of the clothes worn. Body weight was measured to the nearest $0 \cdot 1 \mathrm{~kg}$ with portable digital scales (Omron BF214, Kyoto, Japan), while height was measured to the nearest $0 \cdot 1 \mathrm{~cm}$ using a portable stadiometer (Seca 213, Hamburg, Germany). BMI was calculated as the weight in kilograms divided by the square of height in metres. For the current report, children were classified as thin according to the revised IOTF cut-off points ${ }^{(10)}$. These international gender- and age-specific cut-offs for BMI are defined to pass through BMI of 16, 17 and $18.5 \mathrm{~kg} / \mathrm{m}^{2}$ at age 18 years (thinness grade I, II and III, respectively). Gender and age differences between groups for thinness prevalence were analysed by Pearson's $\chi^{2}$ test for categorical variables. In addition, we compared the prevalence of thinness among children living in regions with different economic development (North-South divide), attending schools with and without a healthfocused educational programme, or having meals available in school settings. The risk of being thin is presented with OR and 95\% CI. Statistical significance was established at $P<0 \cdot 05$. The data were analysed using the statistical software package IBM SPSS Statistics version 21.0.

\section{Results}

During the data collection phase, we recruited 5102 children from forty-two public primary schools. After initial quality control, 214 children were excluded due to missing or inaccurate data. In addition, twenty-seven children younger than 6.00 years or older than 8.99 years were eliminated because they were out of the target age range. In total, 4861 children (95.3\% of initial sample) entered the final analysis. Study participants' characteristics are given in Table 1.

The overall prevalence of thinness was 9.6 (95\% CI 8.8, 10.4)\%. Thinness grade I (mild thinness) was clearly the largest category with a prevalence of 7.6 (95\% CI 6.9, $8.4) \%$, thinness grade II (moderate thinness) was present in 1.7 (95\% CI $1.4,2 \cdot 1) \%$ of children, while thinness grade III (severe thinness) was found in 0.3 (95\% CI $0 \cdot 2,0.5) \%$ of children (Fig. 1). No significant difference in thinness prevalence was found between boys and girls in the 6 years age group $(P=0 \cdot 43)$. Significant gender differences were demonstrated in 7 years and 8 years age groups, with girls more frequently thin than boys $(P=0.00$ and $P=0.02$, respectively). In addition, no significant differences were reported between boys of different ages $(P=0.73)$ nor between girls across the age groups $(P=0 \cdot 60)$. The highest prevalence of thinness was reported in 8-year-old girls (11.9\%, 95\% CI 9.5, 14.3\%), while 7 -year-old boys demonstrated the lowest prevalence of thinness in our cohort $(7 \cdot 6 \%, 95 \%$ CI $6 \cdot 1,9 \cdot 1 \%)$. As for the relative risk, unadjusted $\mathrm{OR}$ indicated a significant risk of being thin for female children (1.44 times higher risk

Table 1 Characteristics of the study sample of 6-9-year-old schoolchildren in Serbia ( $n$ 4861), September-November 2015

\begin{tabular}{|c|c|c|}
\hline Variable & Mean or \% & SD \\
\hline Age (years) & $7 \cdot 7$ & 0.6 \\
\hline Height $(\mathrm{cm})$ & 129.7 & $6 \cdot 8$ \\
\hline Weight (kg) & 28.4 & $6 \cdot 3$ \\
\hline BMI $\left(\mathrm{kg} / \mathrm{m}^{2}\right)$ & $16 \cdot 7$ & $2 \cdot 6$ \\
\hline \multicolumn{3}{|l|}{ Gender } \\
\hline Girls (\%) & $49 \cdot 1$ & \\
\hline Boys (\%) & $50 \cdot 9$ & \\
\hline \multicolumn{3}{|l|}{ Age group } \\
\hline $6.00-6.99$ years $(\%)$ & $16 \cdot 9$ & \\
\hline $7.00-7.99$ years $(\%)$ & $48 \cdot 2$ & \\
\hline $8.00-8.99$ years $(\%)$ & 34.9 & \\
\hline \multicolumn{3}{|l|}{ Living place* } \\
\hline Serbia - North (\%) & $77 \cdot 1$ & \\
\hline Serbia - South (\%) & $22 \cdot 9$ & \\
\hline \multicolumn{3}{|c|}{ Health-focused educational programme in school } \\
\hline Yes (\%) & $10 \cdot 1$ & \\
\hline No $(\%)$ & 89.9 & \\
\hline \multicolumn{3}{|l|}{ School meal availability } \\
\hline Yes (\%) & $80 \cdot 3$ & \\
\hline No $(\%)$ & 19.7 & \\
\hline
\end{tabular}

${ }^{*}$ At the NUTS 1 (Nomenclature of territorial units for statistics) level of European Union territorial classification, Serbia is divided into two regions: Serbia - North (comprising Vojvodina and Belgrade) and Serbia - South (comprising other three regions). 


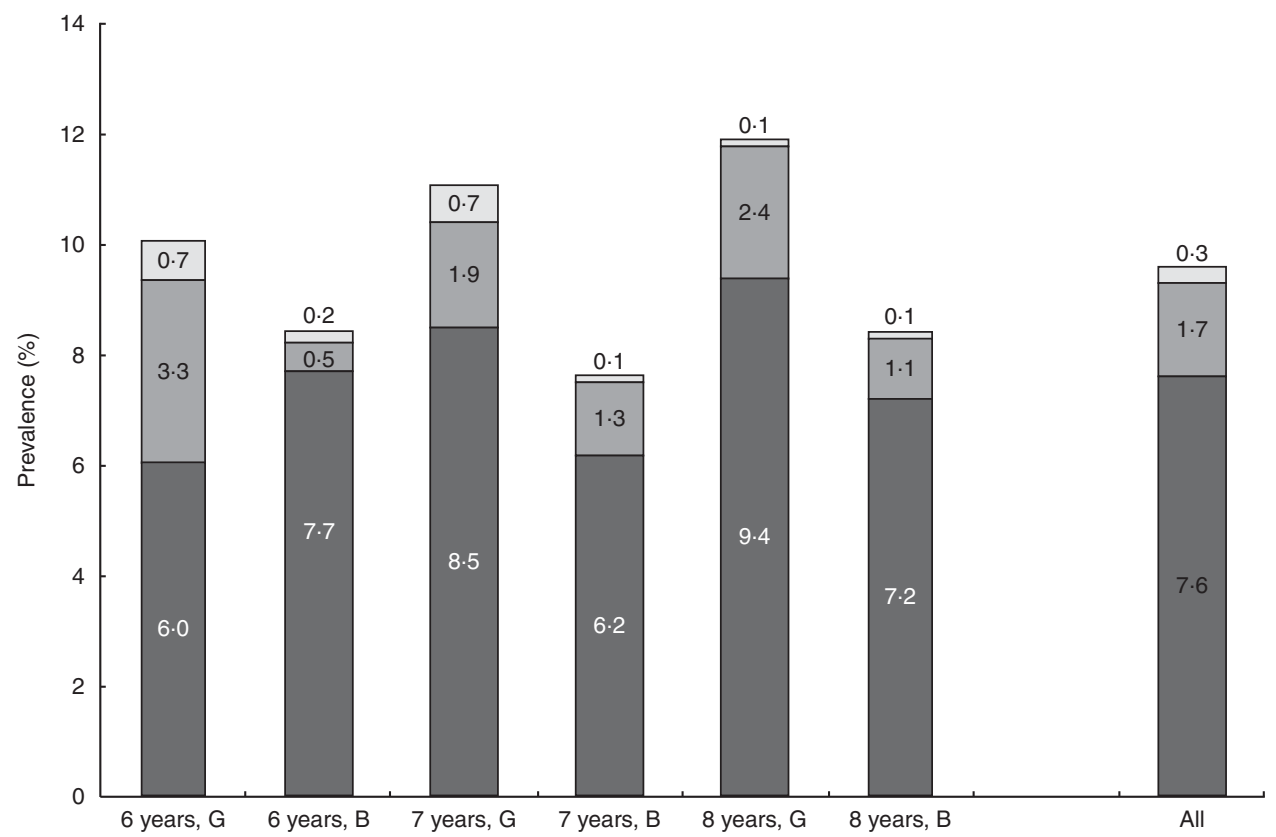

Fig. 1 Prevalence rates (\%) of thinness among 6-9-year-old schoolchildren in Serbia ( $n$ 4861), September-November 2015. Thinness grades are defined as International Obesity Task Force gender- and age-specific cut-offs for BMI (calculated as weight in kilograms divided by the square of height in metres) to pass through BMl of $18.5 \mathrm{~kg} / \mathrm{m}^{2}$ (grade I or mild thinness; $\square$ ), $17.0 \mathrm{~kg} / \mathrm{m}^{2}$ (grade II or moderate thinness; $\square$ ) and $16.0 \mathrm{~kg} / \mathrm{m}^{2}$ (grade III or severe thinness; $\square$ ) at age 18 years (G, girls; B, boys)

Table 2 OR for thinness based on International Obesity Task Force criteria, by age, gender, living place, and health-focused educational programme and meal availability in school settings, among 6-9-year-old schoolchildren in Serbia ( $n$ 4861), September-November 2015

\begin{tabular}{|c|c|c|c|c|c|}
\hline & $n$ & Thinness (\%) & Unadjusted OR & $95 \% \mathrm{Cl}$ & $P$ \\
\hline \multicolumn{6}{|l|}{ Age } \\
\hline $6.00-6.99$ years & 824 & $9 \cdot 2$ & 1.00 & Ref. & - \\
\hline $7.00-7.99$ years & 2341 & $9 \cdot 3$ & 1.01 & $0.77,1.33$ & 0.92 \\
\hline $8.00-8.99$ years & 1696 & $10 \cdot 1$ & 1.10 & $0.83,1.47$ & 0.50 \\
\hline \multicolumn{6}{|l|}{ Gender } \\
\hline Boys & 2386 & $8 \cdot 0$ & 1.00 & Ref. & - \\
\hline Girls & 2475 & $11 \cdot 1$ & 1.44 & $1.18,1.74$ & 0.00 \\
\hline \multicolumn{6}{|l|}{ Living place } \\
\hline Serbia - North & 3746 & $9 \cdot 1$ & 1.00 & Ref. & \\
\hline Serbia - South & 1115 & 11.0 & 1.23 & $0.99,1.53$ & 0.06 \\
\hline \multicolumn{6}{|c|}{ Health-focused educational programme in school } \\
\hline Yes & 490 & 6.5 & 1.00 & Ref. & \\
\hline No & 4371 & $9 \cdot 9$ & 1.57 & $1 \cdot 08,2 \cdot 28$ & 0.02 \\
\hline \multicolumn{6}{|c|}{ School meal availability } \\
\hline Yes & 3906 & $9 \cdot 9$ & 1.00 & Ref. & \\
\hline No & 955 & $8 \cdot 3$ & 0.81 & $0.62,1.04$ & 0.13 \\
\hline
\end{tabular}

Ref., reference category.

compared with male children) and children attending schools where no health-focused educational programmes were available (1.57 times more likely to be thin than peers enrolled in schools with such programmes). In addition, OR for thinness tended to be higher in children living in an economically disadvantaged region of South Serbia (1.23 times higher compared with North Serbia residents). No significant risk was associated with certain age group or school meals availability (Table 2).

\section{Discussion}

In the era of the obesity pandemic, thinness has received less consideration in public health research. Nevertheless, it might have significant health consequences in children and adolescents. Since there was a lack of reliable and internationally comparable data on thinness in young Serbian school-aged children, the present study has focused on thinness prevalence in a nationally representative sample of Serbian 6-9-year-old schoolchildren 
according to revised IOTF cut-offs. A rather high overall prevalence of thinness reported in our study (9.6\%) highlights this malnutrition disorder as an emerging health issue that should trigger public health policies to tackle thinness, especially in girls of young age.

In comparison to thinness prevalence in several high-income European countries ${ }^{(11-16,18)}$, Australia ${ }^{(25)}$ and $\mathrm{USA}^{(21)}$, the prevalence of thinness in Serbia is moderately higher, and it is particularly applicable to girls. It appears that over $10 \%$ of Serbian girls in all age groups were underweight, with up to $4 \%$ of girls suffering from moderate and severe thinness. The present study was not designed to explore the attributable causes of thinness among children, although the high prevalence is likely driven by possible exposure of all children (girls in particular) to specific sociocultural pressures to achieve and maintain a thin figure even at the youngest age. Cultural ideals of beauty and physical attractiveness stereotypes may be reaching very young girls through popular videos and books, and thus affect their body image, development of body dissatisfaction and drive for thinness ${ }^{(26)}$. A thinness bias has been found in pre-adolescent girls, with thinness being associated with femininity, good looks and other positive personality traits ${ }^{(26,27)}$. Another reason that drives high underweight rates among Serbian schoolchildren might be related to poor nutritional habits shaped by low economic power or poor dietary education of affected families, which requires further investigation. Our results confirm that living in an economically disadvantaged region may expose children to a higher risk of being thin, since participants from economically disadvantaged South Serbia were more likely to be underweight than their counterparts from the North region. Regional disparities in Serbia have increased significantly during the socio-economic transition, resulting in a North-South divide ${ }^{(28)}$. Furthermore, it turned out that school health education programmes might have a protective effect in terms of thinness prevalence, probably by teaching children about healthy lifestyle behaviours, including diet. In addition, some cases of undernutrition might be explained by the intergenerational transmission of thinness, where children's low weight-for-height is within the healthy zone and is related to hereditary factors ${ }^{(29)}$. Moreover, we found that the percentage of thin children in our study (9.6\%) exceeded the percentage of obese children (6.9\%) reported previously in the same cohort of boys and girls ${ }^{(24)}$, suggesting a possible double burden of childhood malnutrition at the population level in Serbia. This double burden of malnutrition implies the coexistence of both undernutrition (thinness) and overnutrition (overweight and obesity) in the same population across the life course ${ }^{(30)}$. Actually, thinness and obesity may share very similar causal mechanisms related to diet, physical activity and sociodemographic environment ${ }^{(31)}$. As a middle-income country with its economy in transition, Serbia might fit the profile of a country susceptible to the double burden of malnutrition ${ }^{(32)}$, so integrated action tackling all forms of malnutrition should be provided by health and public authorities.

However, several limitations must be considered when the present study's findings are interpreted. The study population included only 6-9-year-old children; it remains unknown whether thinness prevalence changes throughout childhood. With a limited number of variables evaluated, possible causes or cofactors of thinness profiles in children could not be reliably identified. In particular, future studies should correlate additional indices of malnutrition (e.g. biochemical markers, advanced anthropometric variables) with children's health profiles (e.g. blood pressure, lipid profiles, dietary habits, level of physical activity) to understand health risks associated with thinness in young age.

\section{Conclusion}

In conclusion, it appears that thinness affects approximately one in ten Serbian schoolchildren aged 6-9 years, with young girls and children from economically disadvantaged areas particularly susceptible to this condition. Our study describes the overlooked yet rather prevalent phenomenon of childhood thinness in Serbia, and invites the collection of additional information from other resources to address research gaps. A systematic approach to health education and regular monitoring of thinness prevalence in children is of special importance given the role undernutrition in this age has for modelling the long-term health of individuals and populations.

\section{Acknowledgements}

Financial support: This study was partly supported by the WHO (grant number 2015-540940); the Serbian Ministry of Education, Science and Technological Development (grant number 175037); the Provincial Secretariat for Higher Education and Scientific Research (grant number 114-451-710); the Faculty of Sport and PE, University of Novi Sad (2016 Annual Award); and the Center for Health, Exercise and Sports Sciences (grant number 16-08-15). The funders had no role in the design, analysis or writing of this article. Conflict of interest: None. Authorship: V.D. acquired the data, conducted data analysis, interpreted the data, assisted in the conception of the article and drafted the article. J.J. assisted in the conception and design of the study, interpreted the data and revised the article critically for important intellectual content. S.R. acquired the data, assisted in the interpretation of the data and revised the article critically for important intellectual content. I.M. acquired the data, assisted in the interpretation of the data and revised the article critically for important intellectual content. P.B. acquired the data, assisted in the 
interpretation of the data and revised the article critically for important intellectual content. S.M.O. conceived and designed the study, acquired the data, assisted in the analysis and interpretation of the data, drafted the article and revised the article critically. Ethics of human subject participation: This study was conducted according to the guidelines laid down in the Declaration of Helsinki and all procedures involving human subjects were approved by the Serbian Ministry of Health and Ministry of Education, Science and Technological Development (337-00-00122/ 2015-06). Written informed parental consent was obtained prior to the child's enrolment in the study.

\section{References}

1. de Onis M \& Branca F (2016) Childhood stunting: a global perspective. Matern Child Nutr 12, Suppl. 1, 12-26.

2. Ng M, Fleming T, Robinson M et al. (2014) Global, regional, and national prevalence of overweight and obesity in children and adults during 1980-2013: a systematic analysis for the Global Burden of Disease Study 2013. Lancet 384, 766-781.

3. Scrimshaw NS \& SanGiovanni JP (1997) Synergism of nutrition, infection, and immunity: an overview. Am J Clin Nutr 66, issue 2, 464S-477S.

4. Kodama H (2010) Problems of underweight in young females and pregnant women in Japan. Japan Med Assoc J 53, 285-289.

5. Engle PL (2010) INCAP studies of malnutrition and cognitive behavior. Food Nutr Bull 31, 83-94.

6. Nyaradi A, Li J, Hickling S et al. (2013) The role of nutrition in children's neurocognitive development, from pregnancy through childhood. Front Hum Neurosci 7, 97.

7. van Grieken A, Renders CM, Wijtzes AI et al. (2013) Overweight, obesity and underweight Is associated with adverse psychosocial and physical health outcomes among 7-year-old children: the 'Be Active, Eat Right' study. PLOS ONE 8, e67383.

8. Wake M, Clifford SA, Patton GC et al. (2013) Morbidity patterns among the underweight, overweight and obese between 2 and 18 years: population-based cross-sectional analyses. Int J Obes (Lond) 37, 86-93.

9. Cole TJ, Flegal KM, Nicholls D et al. (2007) Body mass index cut-offs to define thinness in children and adolescents: international survey. BMJ 335, 194-197.

10. Cole TJ \& Lobstein T (2012) Extended international (IOTF) body mass index cut-offs for thinness, overweight and obesity. Pediatr Obes 7, 284-294.

11. Péneau S, Salanave B, Rolland-Cachera MF et al. (2010) Prevalence of childhood thinness, overweight and obesity in France, using several references. Sante Publique France. http:// invs.santepubliquefrance.fr/content/download/14262/82700/ version/1/file/ICO_2010.pdf (accessed December 2017).

12. de Sousa Lopes HM (2012) Diagnostic accuracy of CDC, IOTF and WHO criteria for obesity classification in a Portuguese school-aged children population. Master of Public Health Dissertation, University of Porto.

13. Heinen MM, Murrin C, Daly L et al. (2014) The Childhood Obesity Surveillance Initiative (COSI) in the Republic of Ireland: Findings from 2008, 2010 and 2012. Dublin: Health Service Executive.

14. Moraeus L, Lissner L \& Sjöberg A (2014) Stable prevalence of obesity in Swedish schoolchildren from 2008 to 2013 but widening socio-economic gap in girls. Acta Paediatr 103, 1277-1284.

15. Pearce A, Rougeaux E \& Law C (2015) Disadvantaged children at greater relative risk of thinness (as well as obesity): a secondary data analysis of the England National Child Measurement Programme and the UK Millennium Cohort Study. Int J Equity Health 14, 61.

16. Schönbeck Y, van Dommelen P, HiraSing RA et al. (2015) Thinness in the era of obesity: trends in children and adolescents in The Netherlands since 1980. Eur J Public Health 25, 268-273.

17. Smetanina N, Albaviciute E, Babinska V et al. (2015) Prevalence of overweight/obesity in relation to dietary habits and lifestyle among 7-17 years old children and adolescents in Lithuania. BMC Public Health 15, 1001.

18. Nilsen BB, Yngve A, Sjöberg A et al. (2016) Using different growth references to measure thinness and overweight among Swedish primary school children showed considerable variations. Acta Paediatr 105, $1158-1165$.

19. Ahrens W, Pigeot I, Pohlabeln H et al. (2014) Prevalence of overweight and obesity in European children below the age of 10. Int J Obes (Lond) 38, Suppl. 2, 99-107.

20. Boddy LM, Hackett AF \& Stratton G (2009) The prevalence of underweight in 9-10-year-old schoolchildren in Liverpool: 1998-2006. Public Health Nutr 12, 953-956.

21. Lazzeri G, Rossi S, Kelly C et al. (2014) Trends in thinness prevalence among adolescents in ten European countries and the USA (1998-2006): a cross-sectional survey. Public Health Nutr 17, 2207-2215.

22. Chirita-Emandi A, Barbu CG, Cinteza EE et al. (2016) Overweight and underweight prevalence trends in children from Romania - pooled analysis of cross-sectional studies between 2006 and 2015. Obes Facts 9, 206-220.

23. Pillas D, Marmot M, Naicker K et al. (2014) Social inequalities in early childhood health and development: a European-wide systematic review. Pediatr Res 76, 418-424.

24. Djordjic V, Radisavljevic S, Milanovic I et al. (2016) WHO European Childhood Obesity Surveillance Initiative in Serbia: a prevalence of overweight and obesity among 6-9-year-old school children. J Pediatr Endocrinol Metab 29, 1025-1030.

25. O'Dea JA \& Dibley MJ (2014) Prevalence of obesity, overweight and thinness in Australian children and adolescents by socioeconomic status and ethnic/cultural group in 2006 and 2012. Int J Public Health 59, 819-828.

26. Herbozo S, Tantleff-Dunn S, Gokee-Larose J et al. (2004) Beauty and thinness messages in children's media: a content analysis. Eat Disord 12, 21-34.

27. Pine KJ (2001) Children's perceptions of body shape: a thinness bias in pre-adolescent girls and associations with femininity. Clin Child Psychol Psychiatry 6, 519-536.

28. Mijacic D \& Paunovic B (2011) Regional disparities in Serbia. Ekonom Pred 59, 379-389.

29. Whitaker KL, Jarvis MJ, Boniface D et al. (2011) The intergenerational transmission of thinness. Arch Pediatr Adolesc Med 165, 900-905.

30. Shrimpton R \& Rokx C (2012) The Double Burden of Malnutrition: A Review of Global Evidence. Washington, DC: World Bank.

31. Doak CM, Adair LS, Monteiro C et al. (2000) Overweight and underweight coexist within households in Brazil, China and Russia. J Nutr 130, 2965-2971.

32. Doak CM, Adair LS, Bentley M et al. (2005) The dual burden household and the nutrition transition paradox. Int $J$ Obes (Lond) 29, 129-136. 